\title{
La Textología Contrastiva - método de análisis para la traducción de textos publicitarios
}

\section{Introducción}

El objetivo del siguiente artículo es aplicar el enfoque de la Textología Contrastiva al género textual de los anuncios publicitarios impresos, con el propósito de poner de relieve las convenciones textuales y las prácticas discursivas que rigen dicho género. El presente estudio pretende mostrar la idoneidad del enfoque como método de análisis para la traducción de los textos mediales como son los publicitarios.

La primera parte, de orden más bien teórico, está dedicada a la importancia de la perspectiva contrastiva en la traducción. A continuación, se describe el enfoque de la Textología Contrastiva, presentando las ideas principales de los autores más relevantes en este campo. La segunda parte, ya de índole práctica, expone el análisis cualitativo de los recursos prototípicos de las prácticas discursivas en alemán y en español, basado en un corpus significativo de anuncios publicitarios. Por último, se examinan algunas consecuencias que se derivan de la aplicación de este enfoque contrastivo para la traducción de este tipo de género.

\section{La perspectiva contrastiva en la teoría de la traducción}

El traductor -¿qué duda cabe?- es un mediador intercultural entre mundos textuales, definidos por los elementos deícticos y referenciales ${ }^{1}$. Los textos están insertados en condiciones de producción y de recepción específicas, únicas y singulares. El traductor sólo es capaz de producir una traducción adecuada con relación al destinatario y a la función comunicativa si analiza las convenciones y las normas textuales que rigen un determinado género.

En este sentido, Hurtado Albir (1999) señala que una comparación sistemática de las características textuales y discursivas que componen las convenciones de un género son de suma importancia tanto para la práctica traductora como para la didáctica de la traducción.

Estos análisis, que introducen consideraciones de tipo contrastivo desde un punto de vista de funcionamiento de los textos (elementos de coherencia y cohesión, tipologías textuales), son de sumo interés, ya que se efectúa un desplazamiento de la contrastividad en el plano de la lengua a la contrastividad textual, mucho más cercana a la realidad en que se mueve el traductor. (Hurtado Albir 1999:19)

La traducción de un texto publicitario a otra cultura conlleva que los nuevos receptores entiendan el anuncio meta sin dificultad y que produzca en ellos el mismo efecto apelativo/persuasivo que en los lectores de la lengua original. Para ello, el traductor ha de conocer los distintos recursos lingüísticos y pragmáticos que caracterizan el discurso publicitario en ambas culturas.

La Traductología ${ }^{2}$, con el fin de elaborar una teoría de la traducción que describa la naturaleza ${ }^{3}$ de la traducción en todas sus vertientes -teoría, descripción, historia, práctica-, no puede dejar de lado la perspectiva contrastiva. Carbonell i Cortés (1999) hace mención explícita de la importancia acerca de la perspectiva contrastiva en la teoría de la traducción.
Una teoría de la traducción debe estudiar los modos de construcción del texto desde una perspectiva contrastiva, (...) en cuanto determinado por la cultura de una comunidad y contrastado con la construcción del texto en la lengua y cultura de destino.

(Carbonell i Cortes 1999:138/139)

Kussmaul (1995) lamenta que la teoría de la traducción no se haya ocupado de manera más detallada y exhaustiva de los estudios contrastivos aplicados a la traducción, sobre todo, en cuanto a tipos textuales que no son literarios.

In professional translation, text-types of the non-literary kind play an important part, and one would expect them to have been the object of translation studies. However, so far we have, it seems, been much more in favour of building "models" than studying text material on a constrastive basis. (Kussmaul 1995:72)

Los traductólogos citados ponen de manifiesto que los estudios sistemáticos en torno a los aspectos contrastivos cuyo objeto de análisis sean las diferencias y similitudes textológicas existentes entre distintos tipos textuales pertenecientes a dos o más culturas son de máxima relevancia para la teoría de la traducción.

Con el fin de dar respuesta a estas exigencias consideramos que el enfoque denominado Textología Contrastiva resulta en su concepción metodológica idóneo como paso previo al acto traslativo. Nacido en los años 80, aúna los planteamientos de la lingüística contrastiva y la lingüística del texto. Dicho enfoque permite analizar tanto la organización del texto a nivel macrotextual como las convenciones discursivas que reflejan los recursos estilísticos que posee cada cultura y que caracterizan un género determinado. Partiendo de este planteamiento han salido interesantes estudios que aportan nuevas contribuciones a la Traductología 4 .

\section{La Textología Contrastiva}

Dos son los autores que han introducido este término en la lingüística y la traductología marcando las pautas metodológicas. El primero es R.K.K. Hartmann con la publicación del libro Contrastive Textology en 1980. Un año más tarde aparece un artículo del lingüista alemán B. Spillner (1981): „Textsorten im Sprachvergleich. Ansätze zu einer Kontrastiven Textologie". Podemos clasificar dichos estudios como hitos de esta joven subdisciplina ${ }^{5}$. Ambos autores utilizan el mismo término, en cambio, no comparten el mismo planteamiento conceptual y metodológico. El enfoque de Hartmann (1980) está orientado hacia una descripción teórica de la Textología Contrastiva. Por otra parte, el enfoque de Spillner (1981) se basa en el análisis empírico de los géneros textuales. Ambos enfoques reivindican el análisis de los contrastes lingüísticos a nivel textual y el estudio de las convergencias y divergencias de géneros textuales en dos o más culturas.

\subsection{El enfoque de Hartmann}

Hartmann (1980) se propone aunar la lingüística contrastiva y el análisis del discurso construyendo, de esta forma, una teoría de la Textología Contrastiva. 
By reviewing the hypothesis put forward in the various fields, we can see which are compatible and thus capable of contributing towards a com pound theory of 'contrastive textology'. (CT) (Hartmann 1980:31)

Esta teoría se fundamenta en la línea de la estilística comparada de Vinay/Darbelnet (1958), que constituye, en su opinión, "the first viable brand of contrastive textology" (Hartmann 1980: 33). Basándose en las tres dimensiones semióticas -la pragmática, la sintaxis y la semántica del texto-, Hartmann distingue tres tipos de 'textologías' diferentes, a saber: la textología comunicativa, la textología combinatoria y la textología referencial. El componente pragmático combina el discurso con la variedad funcional cuyo resultado sería una textología comunicativa, que tiene sus raíces en la clasificación de los géneros desde la perspectiva de la retórica, la dialectología, la estilística y el estudio de los registros. El componente sintagmático se refiere al encadenamiento de las partes discursivas que forman un texto completo. Hartmann entiende por ello una textología combinatoria. La textología referencial se deriva del com ponente semántico que hace referencia a las diferentes maneras en que la información referencial está distribuida en tre los elementos constitutivos de un texto

Hartmann describe, posteriormente, el gran alcance de la textología contrastiva para el amplio campo de estudio de la lingüística contrastiva, para el cual encuentra diez disci plinas de aplicación ${ }^{6}$, siendo la traducción una de las disciplinas más idóneas para la metodología de la Textología Contrastiva: "Translation, CT 8, is one of the topics par excellence of contrastive textology" (Hartmann 1980:47).

En este sentido, el autor expone dos razones, a saber: 1) Dado que la comunicación se realiza a través de textos, no es posible traducir palabras u oraciones aisladas, ya que éstas forman parte de un discurso completo que, a su vez, está circunscrito en un particular contexto de una situación 2) La traducción del discurso sólo es viable si se conocen las estructuras equivalentes en la lengua hacia la que se traduce. Tal conocimiento sólo se alcanza a través de la comparación de la Textología Contrastiva. Hartmann enfatiza la importancia de las convenciones estilísticas, definiéndolas como rasgos distintivos de cada tipo textual, aparte del sig nificado de las palabras y del encadenamiento sintáctico de las palabras.

To translate each of the sentences of the sample passage, we should have to know not only what the corresponding lexical and grammatical units are as between the source and the target languages, but also what stylistic conventions are used in each of the text types from which the individual sentences are extracted. (Hartmann 1980:51)

\subsection{El enfoque de Spillner}

Spillner (1981) dibuja, en su artículo "Textsorten im Sprachvergleich. Ansätze zu einer Kontrastiven Textologie", la Textología Contrastiva como área de estudio que se fundamenta en la comparación de las características típicas de un género textual perteneciente a dos sistemas lingüísticos. La Textología Contrastiva, según Spillner, ha de analizar las convenciones textuales de los distintos géneros ${ }^{7}$ y debe mostrar con qué medios textuales se manifiestan estas convenciones en los dos sistemas lingüísticos. El tertium comparationis está representado por las convenciones textuales. Spillner hace una distinción terminológica entre la textología contrastiva y la lingüística del texto contrastiva. Ésta última compara los procedimientos textuales en un sentido estricto. Aquí el tertium comparationis no son las convenciones, como en el caso de la textología, sino el mismo texto.

Es wird daher vorgeschlagen, eine Kontrastive Textlinguistik, die die Geltung der im engen Sinne textlinguistischen Prozeduren und Regeln in Einzelsprachen vergleicht, zu unterscheiden von einer Kontrastiven Textologie, die die Charakteristika von Textsorten auf allen Sprachebenen interlingual vergleicht. (Spillner 1981:243)

Los contrastes entre los géneros textuales, según este autor, están determinados por las condiciones extralingüísticas y socioculturales, así como por las convenciones y los recursos textuales propios de cada lengua. Por lo tanto, la Textología Contrastiva ha de analizar tanto los fenómenos lingüísticos como los elementos culturales y dar respuesta a cómo éstos influyen en la estructura del texto.

Neben sprachlichen Phänomenen hat die Kontrastive Textologie also auch landeskundliche Realien zu berücksichtigen, allerdings nur wenn und insofern sie sich in der Textstruktur niederschlagen. (Spillner 1981:248)

Spillner (1981) desarrolla seis métodos diferentes para el análisis contrastivo, a saber:

a) Comparación del sistema lingüístico a nivel textual (textlinguistischer Systemvergleich): Esto implica el análisis de los procedimientos textuales (constitución textual, coherencia, cohesión, etc.) a nivel de la langue.

b) Comparación de la frecuencia y las normas (Frequenz und Normvergleich): Este método pone de relieve la frecuencia de procedimientos textuales y las normas lingüísticas existentes a nivel de la parole.

c) Análisis de los errores a nivel textual (textlinguistische Fehleranalyse): Se trata de las características en cuanto a las convenciones textuales se refiere y su utilidad para la evaluación de errores.

d) Comparación de textos traducidos (Übersetzungsvergleich): Se entiende por ello el análisis de textos con sus traducciones.

e) Comparación de textos paralelos (Paralleltextvergleich): Es la comparación de textos entre los que no existe una relación traslativa, no obstante, dichos textos se agrupan por razones temáticas y pragmáticas

f) Comparación de la retórica y la estilística normativa (Vergleich der normativen Rhetorik und Stilistik): Se analizan las convenciones que vienen impuestas por instituciones (por ejemplo, normativas para la redacción de documentos públicos, como son el testamento, el contrato compra-venta, etc.).

En suma, ambos autores ofrecen una visión detallada de lo que, en su opinión, debe constituir la disciplina de la Textología Contrastiva en cuanto a su campo de actuación y a su aplicación. Hartmann (1980) intenta aunar en su enfoque disciplinas tan diversas como el análisis del discurso, la traductología, la estilística, la lingüística del texto, el análisis de variedades, etc. Sin embargo, no logra elaborar una metodología propia de la Textología Contrastiva que se pueda poner en práctica para el análisis contrastivo. Incluso en un artículo publicado en 1996, el propio Hartmann (1996) no aporta nuevas ideas. El enfoque de Spillner (1981), por otra parte, está orientado hacia la aplicación práctica, ya que describe una metodología que ejemplifica mediante el análisis del género del anuncio matrimonial (alemán-francés). En este estudio, Spillner analiza la utilización de los marcadores discursivos, los actos de habla y la estructura de los párrafos, a fin de mostrar las convenciones de este tipo de género. 
Una vez expuestos los conceptos más relevantes de la Textología Contrastiva, aplicamos los parámetros teóricos a un estudio analítico para el cual diseñamos un procedimiento metodológico, con el fin de identificar y describir los recursos lingüísticos y pragmáticos convergentes y divergentes del mensaje publicitario en las culturas alemana y española. Asimismo, ahondamos en la utilidad del estudio de los contrastes para la traducción de los textos publicitarios.

\section{Los contrastes culturales y lingüísticos de los anuncios publicitarios}

La Textología Contrastiva representa hoy en día un enfoque atractivo para el análisis de los contrastes lingüísticos y culturales de los géneros textuales. Muestra de ello son las numerosas publicaciones que han aflorado en la década de los noventa siguiendo esta línea metodológica ${ }^{8}$. Curiosamente la investigación en este campo se concentra mayoritariamente en los países germano-parlantes. Pöckl (1999) calcula que dos tercios de todos los trabajos existentes en este campo provienen del ámbito cultural germano (Alemania y Austria), el $10 \%$ se encuentra en países anglosajones, y una pequeña parte en países de la Romania.

La gran parte de los estudios se centra en el análisis de géneros textuales con un mediano o alto grado de estructuras convencionalizadas, como son el género textual del anuncio de trabajo (Arntz 1990), la receta de cocina o los anuncios de contacto (Eckkrammer et al. 1999). Sin embargo, son los géneros menos convencionalizados que resultan más interesantes para el análisis de los contrastes. Consideramos precisamente que los géneros creados por los medios de comunicación representan un campo sumamente fructífero para un estudio contrastivo.

Hier liegen international verbreitete kulturelle Elemente vor, was eine Voraussetzung für die Herausbildung von (ebenfalls international verbreiteten) kulturspezifischen Textsorten und -stilen darstellt. (Androutsopoulos 2001:35)

El anuncio publicitario constituye un género textual que se caracteriza por su complejidad semiótica y pragmática. Los diversos elementos comunicativos desempeñan diferentes funciones pragmáticas dentro del texto publicitario. En este sentido, el diseño general del anuncio cobra especial relevancia, ya que desempaña un papel primordial a la hora de suscitar el interés del receptor. El lenguaje publicitario utiliza todos los recursos lingüísticos que tiene a su alcance, con el fin de preservar su carácter fundamental: la originalidad.

El corpus que hemos elegido para ejemplificar el análisis contrastivo, recopilado entre los años 2000 y 2002, consta de 35 anuncios en español y 35 en alemán ${ }^{9}$ provenientes del campo de la cosmética de marcas internacionales. Este tipo de publicidad se caracteriza por una internacionalización cultural del mensaje, debido a que los anuncios aparecen con la misma imagen en numerosos países, únicamente las partes verbales del anuncio han sido adaptadas a las diferentes culturas. Así, la publicidad traspasa todas las fronteras, utilizando el valor de la belleza como apelación universal.

\subsection{Propuesta metodología y su aplicación}

Nuestro estudio contrastivo se fundamenta en la comparación de los textos paralelos (Paralleltextvergleich), método, propuesto por Spillner (1981), que consiste en la compara- ción de textos que comparten criterios temáticos y pragmáticos sin tener una relación traslativa. Hemos reunido para nuestro corpus anuncios de un mismo tipo de producto -los productos cosméticos femeninos-, en los cuales el mensaje publicitario consiste en recomendar la utilización del producto y en describir los beneficios 'milagrosos' de su empleo a fin de apelar a la compra del producto.

Cualquier anuncio estandarizado ${ }^{10}$ se interpreta como un original, debido a que el lector, al hojear una revista y ver los anuncios, no percibe, ni debe percibir, que está ante la traducción de un anuncio que pertenece a una campaña publicitaria internacional y aparece de forma estandarizada en una variedad de países, o mejor dicho 'mercados'. Nos apoyamos en las autoras Smith/Klein-Braley (1997) al considerar los textos publicitarios como textos auténticos, ya que por su función apelativa deben vender el producto como si fueran anuncios originales.

Moreover, these texts can be assessed as authentic texts of language $\mathrm{X}$ in their own right. They may have started life as translations, but they have to sell their products as original advertisements. (Smith/Kein-Braley 1997:175)

El marco metodológico que ofrece la Textología Contrastiva no sólo permite contrastar los rasgos interlinguales e interculturales específicos de un género textual, sino que también facilita la interpretación de los resultados dentro de un contexto sociocultural más amplio. Asimismo, a través de este método se pueden examinar tanto los elementos verbales como los elementos visuales que componen este género. Para el estudio contrastivo nos hemos centrado en las partes verbales más significativas de un anuncio, como son el titular, el cuerpo y el eslogan. Siendo conscientes de que la imagen está íntimamente ligada a las partes textuales, no hemos profundizado en el análisis semiótico de la imagen, ya que en los anuncios estandarizados la imagen permanece idéntica en los diversos países y un análisis contrastivo de la imagen donde no se produce ningún cambio de una cultura a otra carece de sentido.

El procedimiento que hemos aplicado se realiza en dos fases: la primera consiste en analizar las características morfosintácticas, pragmáticas y estilísticas de los anuncios a nivel intralingual, para cada lengua por separado. En la segunda fase, se filtran los contrastes existentes entre las dos lenguas.

Con el fin de obtener los rasgos prototípicos del discurso publicitario en las dos lenguas objeto de análisis, la alemana y la española, examinamos las similitudes y las diferencias de las prácticas discursivas. Para este fin, nos centramos en los recursos lingüísticos y pragmáticos empleados en la estrategia argumentativa de la ponderación del producto y de la implicación del receptor.

\subsection{Discusión de los resultados}

Una vez efectuado el análisis contrastivo en las dos fases descritas podemos destacar los resultados más significativos del estudio de los contrastes:

En el discurso publicitario alemán predominan los recursos centrados en la ponderación del producto. Estos resultados se basan en las siguientes observaciones:

En el corpus se encuentra un extenso uso de adjetivos con valor metafórico y superlativo:

1) wohltuende Feuchtigkeit, neues sinnliches Erlebnis, gleichmäßig natürlich strahlender Teint, leichte, geschmeidige Wimpern. 
Los adjetivos y adverbios más utilizados con un valor superlativo en los anuncios en alemán son einzigartig, intensiv y perfekt, un valor supelativo también es expresado por el prefijo ultra-:

(2) einzigartig: Ihre Haut ist einzigartig, weil Ihr Verhalten einzigartig ist, die einzigartige Textur

intensiv: intensives Pflegevergnügen, intensiv feuchtigkeitsspendend

perfekt: perfektes, strahlendes Aussehen, perfekt bei jedem Lich

ultra-: ultra-langer Halt, ultra-leichte Konsistenz

Destaca en los anuncios un rasgo muy típico de la lengua alemana, que es la condensación de la información mediante la formación de compuestos de sustantivos y adjetivos:

(3) Körperpflege-Duft, 24h-Feuchtigkeitsversorgung,

samtweiche Haut, fruchtig-frische Farben

Los compuestos también se forman con elementos extranjeros, sobre todo con anglicismos:

(4) Wet-Look-Lippenstift, Anti-Aging-Pflege, New Skin-System

El uso de anglicismos en el discurso publicitario alemán es notorio. Pero también encontramos algunos casos de elementos galos, aunque éstos son aislados:

(5) einfach délicieux, Feuchtigkeits-Crème-Gel

Los anuncios para este tipo de productos reflejan un alto ín dice de términos pseudo-científicos provenientes del campo bio-medicinal. Estos términos, en algunos casos incluso inventados, tienen la función principal de impresionar al lector y transmitir el mensaje de que el producto anunciado es el resultado de la alta tecnología y la intensa investigación. Encontramos términos como

(6) Micropeptid, Traubenpolyphenole, Auto-Focus-Pigment

A nivel estilístico, se encuentra una amplia variedad de figuras retóricas. Hemos comprobado que las figuras retóricas que más dominan cuantitativamente son los tropos como la hipérbole o la personificación.

(7) Hypérbole: Der neue Lippenstift von Chanel. Weit mehr als nur Farbe Noch nie war ein Make-up so verführerisch.

Personificación: die Kommunikation zwischen Dermis und Epidermis optimiert ..., eine intelligente Pflege

Detectamos que en alemán el uso de porcentajes y los resultados exactos sobre el beneficio del producto están más extendidos que en español.

(8) Die Haut wirkt glatter bei $96 \%$, widerstandsfähiger bei $86 \%$ und jünger bei $\underline{80 \%}$

Mehrere tausend Frauen, 95 \% der Frauen sind mit Capture Esentiell sehr zufrieden.

Tanto la acumulación de términos pseudo-científicos como los datos y porcentajes exactos concuerdan con el estilo publicitario alemán, que se caracteriza por ser informativo, racional y serio, donde los detalles técnicos tienen mucha importancia y la calidad del producto constituye la apelación principal.

También a nivel pragmático comprobamos este hecho, dado que predomina la función fática en los actos de habla al invitar al lector a informarse más detalladamente sobre el producto

(9) Erfahren Sie mehr über The Skincare unter www shiseido.com, Lassen Sie sich beraten.

El tratamiento directo del receptor en el anuncio es una forma muy eficaz en cuanto a la apelación publicitaria se refiere, ya que el consumidor es individualizado entre la gran masa. La forma de tratamiento suele ser de cortesía, ya que los anuncios van destinados a un receptor con un nivel educativo medio-alto. Sin embargo, entre las dos culturas se observan diferencias en el tratamiento del destinatario de los anuncios. El alemán utiliza rigurosamente la forma de cortesía Sie. Tutear al lector equivaldría a no tomar sus problemas en serio y restarle respeto a su persona.

En general, el discurso alemán se presenta más informativo que el español. Los recursos que hemos encontrado en el análisis concuerdan con la tendencia a una concepción individualista por la cual se caracteriza la cultura alemana. Esto se puede apreciar a través de la apelación a valores hedónicos que se centran en el bienestar individual que el producto puede aportar al consumidor, como son

(10) Pflege, Natürlichkeit und Frische

En el discurso publicitario español, con el propósito de impresionar al lector y captar su atención, destaca principalmente la argumentación emocional.

A nivel léxico observamos como recurso significativo la utilización de verbos con un valor connotativo positivo, muestra del estilo verbal del español.

(11) atenuar, estilizar, optimizar, renovar, sosegar, suavizar, revitalizar, acartona

Destaca el uso menos extendido de pseudo-tecnicismos y datos exactos sobre el producto. Esto pone de relieve que el español es en cuanto a la exposición de los beneficios de un producto menos argumentativo que el alemán.

Las figuras retóricas emocionales, como son la exclamación y la metáfora, también son muestra del predominio de los elementos emocionales.

(12) Exclamación: iPOR FIN! Duración a toda prueba isin asfixiar la piel! Metáfora: deleite de los sentidos, alimento de vitalidad

Debido a la utilización menos frecuente de la deixis personal, alternando el usted cortés y el tú menos formal, el estilo del discurso publicitario español es menos directo e insiste en menor grado en la individualización del lector. Este hecho lo podemos atribuir a que la cultura española se caracteriza por una concepción algo más colectivista que la cultura alemana.

Con relación a los valores hedónicos, el discurso español confiere más importancia a la apariencia física que pueda aportar el producto al consumidor que a la calidad, debido a la frecuente utilización de palabras claves como

(13) juventud, belleza

Podemos resumir los resultados en la siguiente tabla:

\begin{tabular}{|l|l|}
\hline ESPAÑOL & ALEMÁN \\
\hline Argumentación emocional & $\begin{array}{l}\text { Argumentación centrada en la } \\
\text { eficacia del producto }\end{array}$ \\
\hline $\begin{array}{l}\text { Verbos con valor connotativo } \\
\text { positivo }\end{array}$ & $\begin{array}{l}\text { Uso de adjetivos con valor } \\
\text { metafórico y superlativo }\end{array}$ \\
\hline $\begin{array}{l}\text { Figuras retóricas: metáfora } \\
\text { o exclamación }\end{array}$ & $\begin{array}{l}\text { Datos exactos sobre el éxito } \\
\text { del producto }\end{array}$ \\
\hline Estilo menos directo & Estilo informativo \\
\hline $\begin{array}{l}\text { Valores hedónicos: } \\
\text { juventud, belleza }\end{array}$ & $\begin{array}{l}\text { Valores hedónicos: } \\
\text { cuidado, naturalidad y frescor }\end{array}$ \\
\hline $\begin{array}{l}\text { Menor grado de } \\
\text { individualización del receptor }\end{array}$ & Individualización del receptor \\
\hline
\end{tabular}

Tabla 1: Convergencias y divergencias discursivas 


\subsection{Consecuencias para la traducción}

Mediante el análisis contrastivo e intercultural de un corpus representativo en las culturas española y alemana hemos podido poner de manifiesto que cada cultura posee sus recursos específicos para trasladar el mensaje publicitario a otro sistema lingüístico y cultural. Además, el discurso publicitario es transmisor de los propios patrones culturales.

Nos ha guiado la premisa de que el traductor, por su formación y por su conocimiento de la cultura de origen y de la(s) cultura(s) de trabajo, es un experto intercultural que conoce las convenciones discursivas y tipológicas de una multiplicidad de géneros textuales. Este conocimiento le permite realizar una traducción que abarca tanto la función comunicativa que ha de cumplir el texto traducido en la cultura meta, como las expectativas del receptor acerca del género determinadas por la cultura a la que pertenece el receptor. La gran utilidad del análisis de los contrastes lingüísticos y culturales para la traducción radica en que el traductor dispone de un instrumento metodológico mediante el cual puede examinar las prácticas discursivas propias de cada cultura. Éstas le orientan para la elaboración de una traducción que se adecue a las expectativas del receptor en cuanto a los rasgos prototípicos de cada género textual y de la función comunicativa que ha de desempañar la traducción en la cultura meta.

De nuestro estudio sobre la traducción de textos publicitarios del español y del alemán se pueden derivar las siguientes implicaciones para el proceso traslativo:

Si el traductor recibe el encargo de traducir un texto publicitario del español al alemán, tendrá que procurar que su traducción esté centrada en la ponderación del producto, describiendo las cualidades del mismo mediante los recursos lingüísticos de adjetivos/adverbios con un valor superlativo, el empleo de figuras retóricas, sobre todo, la hipérbole y la personificación, la aportación de datos exactos, la alusión a valores hedónicos más bien individualistas o el uso exclusivo de la forma de cortesía Sie. Por el contrario, en la traducción de un anuncio del alemán al español el traductor deberá utilizar con más frecuencia verbos con valor connotativo positivo y con un significado sugerente, emplear preferentemente la metáfora sobre otras figuras retóricas, apelar a valores hedónicos que estén relacionados con la apariencia física, así como distinguir en el tratamiento directo del lector entre la forma de cortesía usted y la forma más familiar tú. En definitiva, lo más importante para la traducción de textos publicitarios a tener en cuenta por el traductor es que el discurso publicitario español se caracteriza por la argumentación centrada en la apelación emocional, mientras que el discurso alemán se distingue por una argumentación centrada en la descripción de la eficacia de un producto, por tanto, orientada hacia el contenido. Son estos rasgos prototípicos que determinan la elección de los recursos lingüísticos y pragmáticos para cada una de las culturas.

\section{Conclusión}

Mediante el análisis de los contrastes lingüísticos y culturales, aplicando los procedimientos metodológicos de la Textología Contrastiva, hemos examinado los recursos prototípicos característicos para el discurso publicitario en español y alemán. Se ha puesto de manifiesto que el conocimiento de las prácticas discursivas características de un género textual es de gran utilidad para el traductor, al poder tomar sus decisiones en concordancia con las convenciones y normas textuales que rigen un determinado género textual. Éstas establecen las estrategias que el traductor ha de adoptar a fin de cumplir con la función comunicativa del texto original y las expectativas textuales del receptor, culturalmente determinadas.

\section{Bibliografía}

Androutsopoulos, J. K. (2001): „Textsorten und Fankulturen." Fix / Habscheid / Klein (2001), 33-50

Arntz, R. (1990): "Überlegungen zur Methodik einer ,Kontrastiven Textologie'." Arntz, R. (ed.): Übersetzungswissenschaft: Ergebnisse und Perspektiven. Festschrift für Wolfram Wilss zum 65 Geburtstag. Tübingen: Narr, 393-405.

Biber, D. (1990): "Methodological Issues Regarding Corpus-based Analyses of Linguistic Variation." Linguistic and Literary Computing 5/3, 257-269.

Carbonell i Cortés, O. (1999): Traducción y Cultura. De la ideología al texto. Salamanca: Ediciones Colegio de España.

Drescher, M. (ed.) (2002): Textsorten im romanischen Sprachvergleich. Tübingen: Stauffenburg.

Eckkramer, E. M. / Hödl, N. / Pöckl, W. (1999): Kontrastive Textologie. Wien: De. Praesens.

Fix, U. / Habscheid S. / Klein, J. (eds.) (2001): Zur Kulturspezifik von Textsorten. Tübingen: Stauffenburg.

Hartmann, R. R. K. (1980): Contrastive Textology. Heidelberg, Gross.

Hartmann, R. R. K. (1996): "Contrastive Textology and Corpus Linguistics: on the value of parallel texts." Language Sciences 18, 947-957.

Holmes, J.S. (1972/75): "The Name and Nature of Translation Studies." Holmes, J. S. (ed.): Translated! Papers in Literary Translation and Translation Studies. Amsterdam: Rodopi, 66-80.

Hurtado Albir, A. (1999): Enseñar a traducir. Metodología en la formación de traductores e intérpretes. Madrid: Edelsa.

Hurtado Albir, A. (2001): Traducción y Traductología. Introducción a la Traductología. Madrid: Cátedra

Kussmaul, P. (1995): Training the Translator. Amsterdam / Philadelphia: John Benjamins.

Pöckl, W. (1999): "Kontrastive Textologie." Eckkramer / Hödl / Pöckl (1999), $13-46$.

Smith, V. / Klein-Braley, C. (1997): "Advertising - a five-stage strategy for translation." Snell-Hornby, M. / Jettmoravá, Z. / Kaindl, K. (eds.): Translation as Intercultural Communication: selected papers from EST Congress, Prague 1995. Amsterdam / Philadelphia: John Benjamins, 173-194.

Spillner, B. (1981): "Textsorten im Sprachvergleich. Ansätze zu einer kontrastiven Textologie." Kühlwein, W. / Thome, G. / Wilss, W. (eds.): Kontrastive Linguistik und Übersetzungswissenschaft. Akten des internationalen Kolloquiums, Trier/Saarbrücken, 25.-30.9.1978. München: Fink, 239-250.

Spillner, B. (1983): "Zur kontrastiven Analyse von Fachtexten - am Beispiel der Syntax von Wetterberichten." Zeitschrift für Literaturwissenschaft und Linguistik 51/52, 110-123.

Stolze, R. (1998): "Stereotype - Bilder - Texte - Übersetzungen. Beobachtungen an Werbetexten in Brasilien und Deutschland." Lebende Sprachen 43, 97-104.

Vinay, J.P. / Darbelnet, J. (1958): Stylisitique comparée du français et de l'anglais. Paris: Didier.

Werth, P. (1999): Text Worlds: Representing conceptual space in discourse. Longman: London.

Wotjak, G. (2002): "Textsorten und Sprachvergleich." Drescher (2002), $273-277$.

\section{Notas}

1 Werth (1999) define 'text world' como "... a deictic space, defined initially by the discourse itself, and specifically by the deictic and referential elements in it" (Werth 1999:51). Los elementos deícticos y referenciales definen, pues, el mundo textual. La información deíctica “... defines spatial and temporal relationships as clustering around a notional zero-point (which may represent the speaker's viewpoint or that of some other entity." (Werth 1999:52). La información referencial “... specifies the entities present in the text world together with their properties and interrelationships." (Werth 1999:52)

2 Utilizamos el término traductología para referirnos a la disciplina que estudia la traducción tanto oral, escrita y audiovisual, ya que consideramos que este término recoge la diversidad de los estudios en torno a la traducción.

3 Entendemos aquí naturaleza de la traducción en el sentido de Holmes (1972), que establece dos objetivos fundamentales: "1) to describe the 
phenomena of translating and translation(s) as they manifest themselves in the world of our experience, and 2) to establish general principles by means of which these phenomena can be explained and predicted" (Holmes 1972/88: 71).

4 Sobre todo, en la romanística en Alemania se está trabajando intensamente en el campo de la contrastividad de los géneros textuales en distintas lenguas. Muestra de ello, son diversas recopilaciones de artículos sobre la temática: Eckkramer et. al. (1999), Fix et. al. (2001), Drescher (2002)

5 La Textología Contrastiva se considera como una rama de la lingüística contrastiva, ya que analiza los contrastes lingüísticos a nivel textual.

6 CT 1 national styles, CT 2 register ranges, CT 3 individual styles, CT 4 language planning, CT 5 bilingual lexicography, CT 6 comparative rhetoric, CT 7 integration, CT 8 translating/interpreting, CT 9 bilingual codeswitching, CT 10 foreign language learning.
7 Por género entiende Spillner: "Textsorten sind als "sozial genormte komplexe Handlungsschemas konventionell festgelegt, und diese Konventionen können außersprachlich motiviert sein." (Spillner, 1981:248).

8 Pöckl (1999:25-46) presenta una bibliografía amplia sobre los estudios que se enmarcan en el enfoque de la textología contrastiva, y de ah podemos observar que a partir de la segunda mitad de la década de los noventa empieza un interés masivo por este enfoque, muestra de ello son las numerosas publicaciones.

9 Según Biber (1990), un corpus de 10 textos es suficiente para extraer las características distintivas de un género textual y llegar a resultados generalizados.

10 La estandarización de un anuncio significa que se mantiene el lay-out idéntico en la cultura meta, únicamente se adapta el mensaje verbal. 